\title{
RESIDENT PERCEPTIONS OF SUSTAINABLE TOURISM IN MAINE
}

\author{
M. SCACCIA \& S. DE URIOSTE-STONE \\ School of Forest Resources, University of Maine
}

\begin{abstract}
Tourism has long played a central role in the economy, culture, and livelihoods of the people of the State of Maine. The long-term sustainability of this industry in the state is crucial for the current and future prosperity of both businesses and residents. Sustainable tourism has emerged as a key concept over the past few decades and its tenets have clear applicability within the state. Research on residents' perceptions of tourism impacts and development suggest these assessments to be highly important if a community's tourism industry is to be successful and sustainable in the long term. This study used the SUS-TAS scale modified by Sirakaya (2007) to explore the perceptions of residents who participate in outdoor recreation about sustainable tourism at the state level, and determine if attitudinal differences exist across demographic groups. An online survey was used to assess perceptions following Dillman's 'tailored design method' to refine the overall quality of the instrument, and increase response level. The sample consisted of Maine resident outdoor recreation users. Factor analysis with varimax rotation revealed that seven-factor categories on residents' attitudes of sustainable tourism accounted for $65.7 \%$ of the variance in the responses. The factor on residents' perceived social costs of tourism accounted for more of the total variance than any of the other six factors. The results of this research will provide new insights into essential needs for tourism planning in Maine.
\end{abstract}

Keywords: factor analysis, outdoor recreation, psychometrics, SUS-TAS, survey research.

\section{INTRODUCTION}

\subsection{Background}

Tourism is among the top two industries in the State of Maine; for over 100 years the industry has supported the economy, culture, and livelihood of Mainers. A key concern for tourism planners is how to ensure the long-term sustainability of this industry for current and future generations. According to the UN World Tourism Organization (UNWTO), sustainable tourism 'takes full account of the current and future economic, social and environmental impacts [of tourism] while addressing the needs of visitors, the industry, the environment and host communities' WTO [1]. Sustainable tourism's tenets include environmental sustainability via conserving natural resources, social sustainability by respecting human rights and equitably distributing benefits, and economic sustainability via seeking to generate prosperity at different levels of society for the long-term [2]. Achievement of these tenets requires advanced planning.

The State of Maine - the easternmost state in the continental United States - includes many rural communities that are economically reliant on the success of their outdoor recreation and tourism industries. In 2013, tourism business in Maine generated 88,585 jobs and 
$\$ 5.2$ billion in direct purchases [3]. Environmental quality is especially important for tourism in the state since the majority of visitors participates in nature-based activities, or attracted to areas for their scenic assets including forests, lakes, rivers, and the coastline. Although tourism is essential in most areas of the state, tourism activity is not homogenous across the state and the level of tourism activity residents are exposed to in a given region varies greatly.

In order for the sustainable tourism tenets to be effectively integrated into communities, the support of local residents is imperative, and their attitudes need to be understood. The goal of this study is to understand how Maine residents who participate in outdoor recreation perceive the principles of sustainable tourism within the context of their own communities.

\subsection{Residents' attitudes toward sustainable tourism}

Residents' perceptions of tourism are among the most studied areas within the tourism literature [4]. Research on the topic suggests that residents' perceptions are highly important and must be taken into consideration if a community's tourism industry is to be sustainable [5]. Authors typically examine factors such as community participation in tourism, environmental considerations, social issues, and economic factors when discussing residents' attitudes regarding sustainable tourism.

Residents' attitudes in terms of environmental sustainability have been found to play an important role in tourism development [6]. The balance between environmental protection and the need for development may be closely related to residents' foundational attitudes toward the environment. It has been asserted that residents are the tourism stakeholder group that may be the most likely to support the long-term conservation of natural resources within a given community since they are most likely to have the closest direct relationship to those resources [7].

Social implications of tourism have been central aspects of studies on residents' attitudes toward sustainable tourism. A guiding principle for fostering social sustainability is that at the 'local level, tourism planning should be based on overall development goals and priorities identified by residents' [8]. Social conflict may arise due to cultural impacts derived from tourism if the culture of a community is seen solely as a commercial resource. Sustainable tourism, therefore, seeks to foster respect for the rights and traditions of local residents and their cultural resources.

When evaluating economic sustainability and residents' attitudes toward tourism, it is important that the economic benefits derived from tourism be financially viable in the long term, and provide benefits to a wide variety of residents. Residents may recognize that tourism has a 'unique quality in income generation and distribution compared to many other industries in that it promotes regional development, has a high multiplier effect, and consumes a wide variety of local goods and services' [9].

\subsection{The Sustainable Tourism Attitude Scale [SUS-TAS]}

The SUS-TAS scale was first tested by Choi and Sirakaya [10] using a 51-item survey that measured residents' perceptions through seven factors including (1) Social costs of tourism, (2) Environmental issues, (3) Long-term planning, (4) Perceived economic benefits, (5) Community-centered economy, (6) Importance of visitors' satisfaction, and (7) The importance of maximizing community participation in tourism decisions. The instrument included a series of statements with five-point Likert-type scale ranging from 'strongly agree' to 
'strongly disagree' (see Table 3 for full-scale item descriptions). A variety of authors have used the SUS-TAS instrument or a subsection of the questions in studies across the globe [10-16]. As the reliability and validity of the instrument have been tested, it has been possible to create shortened versions of the scale $[14,16]$

\section{METHODS}

This study measured attitudes of Maine residents who participate in outdoor recreation toward sustainable tourism using the SUS-TAS scale. The research questions addressed were: Are residents who participate in outdoor recreation concerned about the sustainability of the tourism industry in their community? Do attitudes toward sustainable tourism vary among socio-demographic groups?

\subsection{Questionnaire development}

The SUS-TAS questions were reapplied nearly verbatim following the scale developed by Yu et al. [14] that had only 27 items. The online survey design used elements of the Dillman 'Tailored Design Method' [17] to refine the overall quality of the instrument, seek to increase response level via survey design, send multiple invitations to participate, and provide respondents the opportunity to participate in an incentive raffle [17]. Participants were sent up to three follow up invitations. The questionnaire instrument included the following sections: (1) outdoor recreation participation in Maine; (2) the 27-item SUS-TAS scale, and (3) demographic information (zip code, gender, age, level of education, annual household income).

\subsection{Description of the study sample \& data analysis}

The survey sample included individuals that had previously paid a recreation-related fee such as fishing and hunting (deer and moose) licenses, ATV/snowmobile registration fee, and Maine State Parks camping registration, and had voluntarily provided their email address. A total of 8,695 Maine residents who participate in recreation responded to the survey, for a $19 \%$ response rate.

An exploratory factor analysis procedure was conducted to determine the variability in the responses for the SUS-TAS questions [18]. Since the instrument was designed to measure attitudes within seven different categories, a command was written in the analysis to extract seven factor items (to reflect the seven dimensions of the scale). An 'alpha factoring' method was chosen to estimate the constructs that the instrument is measuring in such a way that reliability is maximized [18]. A varimax rotation was used in this analysis since the factors in the SUS-TAS scale were not correlated with each other [19]. A Cronbach's Alpha reliability analysis was conducted to examine the internal consistency of the scale items. For variables that yielded a low Cronbach's alpha score $(<0.70)$, the data outputs for 'Cronbach's alpha if item deleted' were checked to assess the degree that individual items reduced the overall reliability and internal consistency for any constructs [18].

By using One-Way ANOVA analysis (for demographic characteristics including age, annual level of income, level of education, and employment status) and independent sample $t$-tests (for examining age only), it was possible to determine if there were statistically significant differences between their attitudes toward sustainable tourism and their demographic characteristics. The confidence interval for this analysis was set at $(\operatorname{sig}<0.05)$. 


\subsection{Controlling for survey implementation errors}

For this study, nonresponse bias was checked by following a method used by Collum and Daigle [20] where the authors tested the first and last $10 \%$ of respondents and conducted chisquare tests to determine if there were differences. We found there was no statistically significant difference between early and late respondents except for three of the 27 SUS-TAS items. Therefore, it is not believed that these differences had a notable impact on the results of the overall study. The instrument was also pre-tested prior to administering the questionnaire and feedback on question styling and section organizing were incorporated into the final questionnaire.

\section{RESULTS AND DISCUSSION}

\subsection{Demographic profile of SUS-TAS respondents}

The demographic results found that, in terms of gender, $63.4 \%$ of the respondents were male. The majority of participants were between the ages of 52-68 (41.4\%) while $14.2 \%$ were $18-34,39.0 \%$ were $35-51$, and $5.5 \%$ were $69-102$. It was found that the majority had an annual income level $>\$ 80,000(44.5 \%)$ while $39.4 \%$ earned between $\$ 40,000-\$ 79,000$ and $16.4 \%$ earned $\$ 0-\$ 39,999$. For level of education, the great majority could be described as 'well educated' (having a four-year college degree) $(67.1 \%)$ while $18.6 \%$ were 'highly educated' (with a master's degree or higher) and $14.3 \%$ had 'low education' (secondary degree or lower). It was found that - in terms of the recreational behavior of the SUS-TAS respondents $-58.2 \%$ had engaged in some form of hunting, $73.6 \%$ had been recreational fishing, $34.4 \%$ had ridden an all-terrain vehicle (ATV), and 31.9\% had ridden on a snowmobile.

\subsection{Factor analysis of residents' attitudes}

Analysis calculating the means and standard deviations for each of the SUS-TAS constructs found that residents have varying levels of agreement and differing levels of variability in their perceptions. It was found, for example, the maximizing community participation construct was found to have a relatively low-standard deviation about the mean ( $\mathrm{SD}=0.7198)$, it is likely that there is also high agreement among residents regarding this concept (Table 1).

Table 1: The observed means and standard deviations calculated for each of the SUSTAS constructs/factors for the study sample, 2014.

\begin{tabular}{lcc}
\hline Construct/Factor & Mean & Standard deviation \\
\hline Perceived social costs & -0.4781 & 0.8735 \\
Environmental sustainability & 0.2135 & 0.6723 \\
Long-term planning & 1.0979 & 0.6251 \\
Perceived economic benefits & 0.7057 & 0.7533 \\
Community-centered economy & 1.1140 & 0.6142 \\
Ensuring visitors' satisfaction & 0.7930 & 0.5753 \\
Maximizing community participation & 0.5538 & 0.7198 \\
\hline
\end{tabular}


In terms of their attitudes toward environmentally-related issues, a relatively small mean $(\overline{\mathrm{x}}=$ 0.2155) was achieved, which reveals that residents do not, overall, have strong attitudes regarding this concept and are likely to be 'undecided' about the status of their community's' natural environment that the effects that tourism has on it. For the construct relating to perceived social costs, it was found that, overall, residents were more likely to believe that tourism does not impose negative social outcomes for their community, but according to the calculated standard deviation ( $\mathrm{SD}=0.8735$ ), it was the topic that residents were most likely to disagree on.

\subsection{Results of exploratory factor analysis}

The results from the exploratory factor analysis found that the SUS-TAS instrument overall was a statistically reliable means of measuring attitudes of Maine residents who participate in outdoor recreation about sustainable tourism development in their communities (Table 2). The exceptions to this came from individual question items as opposed to the entire model. The results of a KMO test yielded a value of 0.894 and Bartlett's Test of Sphericity generated an approximate chi-square value of 82955.514 and was statistically significant at the $\mathrm{p}<$ 0.001 level. These values indicate that the sample size obtained was adequate for properly conducting a factor analysis and, more importantly, that there was a significant degree of correlation between the factors within the analysis to justify conducting this type of analysis.

With the analysis fixed to extract seven factors, it was found that $65.672 \%$ of the variance in the responses obtained was accounted for by the SUS-TAS instrument. It was clearly found that the factor measuring residents' perceived social costs of tourism accounted for more of the total variance (Table 2). Also, it was found that several of the factors including community-centered economy, ensuring visitors' satisfaction, and maximizing community participation did not account for a very large portion of the total explained variance. Although

Table 2: Summary of the factor analysis conducted on the SUS-TAS variables to explore their reliability.

\begin{tabular}{|c|c|c|c|c|}
\hline \multirow[b]{2}{*}{ Factor } & \multicolumn{4}{|c|}{ Initial eigenvalues } \\
\hline & Factor name & Total variance & $\%$ of variance & Cumulative $\%$ \\
\hline 1 & $\begin{array}{l}\text { Perceived social } \\
\text { costs }\end{array}$ & 6.107 & 22.619 & 22.619 \\
\hline 2 & Long-term planning & 3.721 & 13.782 & 36.400 \\
\hline 3 & $\begin{array}{l}\text { Perceived economic } \\
\text { benefits }\end{array}$ & 2.520 & 9.333 & 45.733 \\
\hline 4 & $\begin{array}{l}\text { Environmental sus- } \\
\text { tainability }\end{array}$ & 1.870 & 6.926 & 52.659 \\
\hline 5 & $\begin{array}{l}\text { community- cen- } \\
\text { tered economy }\end{array}$ & 1.475 & 5.462 & 58.122 \\
\hline 6 & $\begin{array}{l}\text { Ensuring visitors' } \\
\text { satisfaction }\end{array}$ & 1.063 & 3.936 & 62.058 \\
\hline 7 & $\begin{array}{l}\text { Maximizing commu- } \\
\text { nity participation }\end{array}$ & 0.976 & 3.614 & 65.672 \\
\hline
\end{tabular}


Table 3: Results of the rotated factor analysis and Cronbach's alpha values, 2014.

Construct/Question item

Factor loadings Cronbach's alpha

Perceived social costs 0.896

'My community is overcrowded because of tourism'

'Tourism is growing too fast in my community'

'My community's recreational resources are overused

0.801

by tourists'

'Tourists in my community disrupt my quality of life'

Long-term planning 0.857

'Successful management of tourism requires advanced

planning'

'Tourism development needs well-coordinated planning'

0.763

'We need to take a long-term view when planning for

0.753

tourism development'

'When planning for tourism, we can't be shortsighted'

0.683

Perceived economic benefits 0.820

'Tourism is a strong economic contributor to my community'

'Tourism brings new income to my community'

'Tourism generates substantial tax revenue for my local government'

'Tourism benefits other than just tourism-related industries in my community'

Environmental sustainability 0.824

'My community's natural environment is being protected now and for the future'

'Tourism in my community is developed in harmony with the natural environment'

'Tourism development in my community always protects wildlife and natural habitats'

'My community's diversity of nature is valued and

0.709

0.542 protected'

'Tourism development in my community promotes positive environmental ethics'

\section{Community-centered economy 0.742}

'The tourism industry should try to purchase their goods and services within the local community'

'Tourism businesses in my area should try to hire most of their employees from within the community'

'The tourism industry in my area should economically contribute to community improvement efforts' 
Construct/Question item

Factor loadings Cronbach's alpha

Ensuring visitors' satisfaction 0.710

'Tourism businesses in my community must monitor

visitors' satisfaction'

'It is the responsibility of tourism businesses to meet

visitors' needs'

'Tourism businesses in my area should ensure good

quality tourism experiences and opportunities for visitors'

'Community attractiveness is a core element of ecological "appeal" for visitors to my area'

Maximizing community participation 0.559

'Tourism decisions in my area must be made by all members in the community regardless of a person's background'

'Full participation by everyone in my community regarding tourism decisions is a must for successful tourism development'

'Sometimes it is acceptable to exclude residents in my community from tourism development decisions'

it is conventional to retain factors in a model with an eigenvalue $>1$, the factor for maximizing community participation was retained since its value was only slightly below 1 (eigenvalue = 0.976).

The results of the rotated factor analysis yielded either a high or acceptable level of confidence for six of the seven SUS-TAS factors (Table 3). This analysis demonstrated that each of the factors loaded appropriately with their intended construct. Cronbach's Alpha values had acceptable levels for six of the seven constructs. It was found that the perceived social costs construct had the highest alpha score and was, therefore, the factor that was best able to be measured.

The construct for long-term planning also had a high degree of reliability as well as highfactor loadings. The remaining five constructs had a wider range of factor-loading values with some items performing notably better than others. For the perceived economic benefits construct, the scale item 'tourism benefits other than just tourism-related industries in my community' was found to be a less effective measure than the other items in the set. Similarly, for the construct measuring community-centered economic attitudes, the item 'The tourism industry in my area should economically contribute to community improvement efforts' was not a comparably sufficient measure of the construct it intended to measure since it had a lower-factor loading than other items measuring the same construct (0.407). The case where this issue was most apparent was for the attitudes toward maximizing community participation construct. The item 'Sometimes it is acceptable to exclude residents in my community from tourism development decisions' was clearly ineffective at operationalizing the construct it was measuring. This item had a major impact on the Cronbach's Alpha, which resulted in 
Table 4: One-way ANOVA and independent samples t-test results examining residents' overall sustainability index to demographic variables.

\begin{tabular}{lccr}
\hline Demographic variable & F & df & p-value \\
\hline Age & 5.663 & 3 & 0.001 \\
Gender & 0.080 & 7370 & 0.778 \\
Annual income & 1.700 & 2 & 0.183 \\
Length of residence in Maine & 5.715 & 7 & $<0.001$ \\
Level of education & 4.638 & 2 & 0.010 \\
\hline
\end{tabular}

a value of only 0.569 . Further analysis revealed that, if this item was deleted from the scale, the alpha level would increase to 0.689 . Given that an alpha level of 0.70 or higher is desired and 0.60 is considered acceptable, it appears that the other items were able to measure the construct quite well.

The results of one-way ANOVA and independent samples $t$-test (Table 4) revealed that residents overall sustainable tourism attitudes are not different based on gender or annual income $(\mathrm{sig}<0.05 \%)$. These tests also found that there were differences in terms of age, length of residence in the State of Maine, and level of education.

\subsection{Discussion}

When examining previous studies that have implemented the SUS-TAS scale, it is clear that noticeable patterns have emerged in terms of the factor loadings that have been obtained through factor analysis. In this study and studies conducted by Choi and Sirakaya [10] and Yu et al. [14] have all found that the factor for perceived social costs has consistently been the factor with the highest overall reliability. This study, as well as other studies, found that long-term planning has been one of the top three factors. As was found in this study, Choi and Sirakaya [10] and Yu et al. [14] also found the three lowest performing factors, in order, were community-centered economy, ensuring visitors' satisfaction, and maximizing community participation. A factor analysis of the SUS-TAS found that the seven-factor scale accounted for $65.67 \%$ of the variance in responses while Choi and Sirakaya's analysis accounted for $61.5 \%$ of their variance [10]. Testing the reliability of the scale factors using Cronbach's alpha in this study found that six of the seven factors performed at a satisfactory level, and the factor for maximizing community participation was less than adequate. This indicates that certain scale items that measure this construct do not effectively measure what they intend to. In the case of this study, the scale question 'Sometimes it is acceptable to exclude residents from tourism development decisions' generated a weak factor loading (0.569) while the other scale items performed somewhat better. This scale item was responsible for generating a Cronbach's Alpha value of $<0.70$ in this study as well as for Yu et al. [14].

While other studies have not directly examined residents' attitudes toward sustainable tourism through examining demographics, this study did find that resident attitudes can vary based on these types of characteristics. The analysis revealed that there were differences in terms of age, length of residence in the State of Maine, and level of education. The analysis here cannot illustrate whether or not these differences are based on an actual cause and effect relationship or not. 


\section{CONCLUSIONS AND IMPLICATIONS}

The results of this study reveal that, overall, Maine residents who participate in outdoor recreation agree overall with the principles of sustainable tourism, and that they perceived tourism as sustainable in their communities. This study found that Maine residents that participate in outdoor recreation generally believed that tourism in their community (1) Does not impose significant social costs, (2) Tourism is most likely to either have neutral or non-negative effects on their local environment, (3) Should be managed through long-term planning efforts, (4) Tourism provides positive economic benefits to their community, (5) Should be a product of their local economy, (6) Should satisfy the visitors who come to visit their area, and (7) Participation by all members of their community in tourism decision making is essential.

It is clear that, given the major importance of tourism to the State of Maine, it is highly relevant to examine the sustainability of the industry in the state. Applying the tenets of sustainable tourism development throughout the state definitely can provide substantial benefits. Through understanding residents' attitudes toward sustainable tourism, it is possible to prioritize management strategies while respecting the needs and rights of locals. Using the SUS-TAS has proven to, overall, be a reliable means of measuring residents' attitudes. Based on our findings and those from other studies $[10,14,16]$, additional refinement of the maximizing community participation construct and item statements may be required to increase the predictive power of the scale.

\section{REFERENCES}

[1] World Tourism Organization, Making Tourism More Sustainable- A Guide for Policymakers. World Tourism Organization, 2005.

[2] Goeldner, C.R. \& Ritchie, J.R.B., Tourism: Principles, Practices, Philosophies, 12th edn., John Wiley \& Sons, Inc: Hoboken, NJ, 2012. http://dx.doi.org/10.1177/0047287504268234

[3] Maine Office of Tourism: Annual report, p. 23, 2014.

[4] McGehee, N.G. \& Andereck, K.L., Factors predicting rural residents' support of tourism. Journal of Travel Research, 43(2), pp. 131-140, 2004. http://dx.doi.org/10.1177/0047287504268234

[5] Nunkoo, R., Smith, S.L.J. \& Ramkissoon, H., Residents' attitudes to tourism: a longitudinal study of 140 articles from 1984 to 2010. Journal of Sustainable Tourism, 21(1), pp. 5-25, 2013. http://dx.doi.org/10.1080/09669582.2012.673621

[6] Liu, J.C., Sheldon, P.J. \& Var, T., Resident perception of the environmental impacts of tourism. Annals of Tourism Research, 14(1), pp. 17-37, 1987. http://dx.doi.org/10.1016/0160-7383(87)90045-4

[7] Jurowski, C., Uysal, M. \& Williams, D.R., A theoretical analysis of host community resident reactions to tourism. Journal of Travel Research, 36(2), pp. 3-11, 1997.

[8] Cooke, K. Guidelines for socially appropriate tourism development in British Columbia. Journal of Travel Research, 21(1), pp. 22-28, 1982. http://dx.doi.org/10.1177/004728758202100106

[9] Liu, Z. Sustainable tourism development: A critique. Journal of Sustainable Tourism, 11(6), pp. 459-475, 2003. http://dx.doi.org/10.1080/09669580308667216

[10] Choi, H.-S.C. \& Sirakaya, E. Measuring residents' attitude toward sustainable tourism: development of sustainable tourism attitude scale. Journal of Travel Research, 43(4), pp. 380-394, 2005. 
http://dx.doi.org/10.1177/0047287505274651

[11] Sirakaya-Turk, E., Ekinci, Y. \& Kaya, A.G., An examination of the validity of SUS-TAS in cross-cultures. Journal of Travel Research, 46(4), pp. 414-421, 2008. http://dx.doi.org/10.1177/0047287507308328

[12] Rathanyake, C.V. \& Darshi, G.A., An application of sustainable tourism attitude scale (SUS-TAS) in three coastal tourist destinations in the southern province of Sri Lanka. In Role of Managers in a Knowledge Economy. Sri Lanka: Faculty of Management Studies and Commerce University of Sri Jayewardenepura Sri Lanka. pp. 161-170, 2009.

[13] Kvasova, O., Socio-demographic determinants of eco-friendly tourist attitudes and behaviour. Tourism Today: The Journal of the College of Tourism and Hotel Management, 11, pp. 73-95, 2011.

[14] Yu, C.-P. (Simon), Chancellor, H.C. \& Cole, S.T., Measuring residents' attitudes toward sustainable tourism: A reexamination of the sustainable tourism attitude scale. Journal of Travel Research, 50(1), pp. 57-63, 2011. http://dx.doi.org/10.1177/0047287509353189

[15] Vong, M., Valle, P. \& Silva, J., Residents' attitude towards sustainable tourism development in Timor-Leste. In Marketing Places and Spaces: Shifting Tourist Flows, pp. 37-42, 2013.

[16] Zhang, Y., Cole, S.T. \& Chancellor, C.H., Facilitation of the SUS-TAS application with parsimony, predictive validity, and global interpretation examination. Journal of Travel Research, 54(6), pp. 1-14, 2014.

[17] Dillman, D.A., Smyth, J.D. \& Christian, L.M., Internet, Mail, and Mixed-Mode Surveys: The Tailored Design Method (Third), John Wiley \& Sons, Inc: Hoboken, NJ, 2009

[18] Nunnally, J.C. \& Bernstein, I.H., Psychometric Theory, 3rd edn., McGraw-Hill: New York, NY, 1994.

[19] Millsap, R.E. \& Maydeu-Olivares, A., The SAGE Handbook of Quantitative Methods in Psychology. London: SAGE, 2009.

[20] Collum, K.K. \& Daigle, J.J., Combining attitude theory and segmentation analysis to understand travel mode choice at a national park. Journal of Outdoor Recreation and Tourism, 9, pp. 17-25, 2015.

http://dx.doi.org/10.1016/j.jort.2015.03.003 